\title{
Uma leitura sobre o Império do Brasil no contexto do século XIX: diálogo com Ricardo Salles
}

Reading the Brazilian Empire in the Nineteenth Century Context: a Dialogue with Ricardo Salles

\section{Carlos Gabriel Guimarães \\ Professor Associado IV no \\ Departamento de História da \\ Universidade Federal Fluminense \\ (UFF-Niterói/Rio de Janeiro, Brasil) \\ e bolsista de produtividade em \\ pesquisa do Conselho Nacional \\ de Desenvolvimento Científico e \\ Tecnológico (Cnpq). \\ e-mail:cgg@uol.com.br}

\section{Resumo}

0 presente artigo analisa o texto 0 Império do Brasil no contexto do século XIX. Escravidão nacional, classe senhorial e intelectuais na formação do Estado, procurando ressaltar a sua contribuição para o debate historiográfico acerca da construção do Estado Imperial brasileiro durante o Segundo Reinado.

\begin{abstract}
This article analyzes the essay The Brazilian Empire in the Nineteenth Century. National Slavery, Planter Class, and Intellectuals in the Process of the State Building, seeking to highlight its contribution to the historiographical debate on the construction of the Imperial State of Brazil during the Second Empire.
\end{abstract}

Palavras-chave

Estado, classe senhorial, intelectual orgânico, elite estadista

Keywords

State, planter class, organic intellectual, elite-statesman 
GRAMSCI, Antonio. Maquiavel, a política e o Estado Moderno. Tradução de Luiz Mario Gazzeano. $5^{\text {a }}$ edição. Rio de Janeiro: Civilização Brasileira, 1985 Os Intelectuais e a organização da Cultura. $8^{\text {a }}$ edição. Rio de Janeiro: Civilização Brasileira, 1991; MATTOS, IImar Rollof. O Tempo Saquarema. São Paulo: HUCITEC, 1986.

2

Segundo Ricardo Salles, a presença dos

representantes da classe senhorial com sede no Rio de Janeiro foi maior do que a naturalidade de cada presidente do gabinete conforme ressaltou José Murilo de Carvalho. Cf. CARVALHO, José Murilo de A Construção da Ordem e Teatro das Sombras. Rio de Janeiro, EDUFRJ/Relume Dumará, 1996.

3

BARBOSA, Silvana. 0 Conselho de Ministros no Império do Brasil. Locus: revista de história, Juiz de Fora, v.13, n.1, p.52-62, 2007.

4

BERNARDO, João. Gestores, Estado e Capitalismo de Estado. São Paulo: Ensaio, 1985. Agradeço ao prof. João Pinto, Departamento de História da Universidade Federal de Goiás, pelo conhecimento do autor mencionado.

5

Há uma extensa literatura sobre a obra de Antonio Gramsci e a Teoria do Estado Ampliado. Além do próprio Gramsci já destacado, conferir os trabalhos de Nicos Poulantzas e de autores brasileiros como da Profa. Sonia Regina de Mendonça do PPGH/ UFF. Cf. POULANTZAS, Nicos. O Estado, o Poder, o Socialismo. Traduzido por Rita Lima. 3a Edição. Rio de Janeiro: Graal, 1985; MENDONÇA, Sonia Regina. Economia e Política na Historiografia Brasileira: http://www.historia.uff.br/estadoepoder/files/ art01_mendonca_economiaepolitica.pdf; Idem. 0 Patronato Rural no Brasil Recente. Rio de Janeiro: Ed. UFRJ, 2010; Idem. A pesquisa sobre Estado e Poder: balanço historiográfico. In: SILVA, Carla Luciana, CALIL, Gilberto Grassi e KOLING, Paulo José (org.). Estado e Poder: Questões Teóricas e Estudos Históricos. Cascavel: EDUNOESTE, 2011. p.13-34.

6

MARTINS, Maria Fernanda Vieira. A velha arte de governar. Um estudo sobre política e elites a partir do Conselho de Estado (1842-1889). Rio de Janeiro: Arquivo Nacional, 2007.

7

MARTINS, Maria Fernanda. A velha arte de governar: um estudo sobre politica e elites a partir do Conselho de Estado (1842-1889). 2005, 407 f. Tese (Doutorado em História). Programa de Pós-graduação em História Social, Universidade Federal do Rio de Janeiro, Rio de Janeiro, 2005; Idem. 0 Círculo dos grandes: Um estudo sobre política, elites e redes no segundo reinado a partir da trajetória do visconde do Cruzeiro (1854-1889). Loccus: Revista de História, Universidade Federal de Juiz de Fora, v.13, n.1, p.93-122, 2007.

8

A respeito de familia e de rede de sociabilidade cf. BERTRAND, Michel. De la familia a la red de sociabilidad. Revista Mexicana de Sociologia, n.2, v.61, abril-junho de 1999; LEVI, Giovanni. A Herança Material: trajetória de um exorcista no Piemonte do século XVII. Prefácio de Jacques Revel; tradução de Cynthia Marques de Oliveira.
0 texto tem como objetivo analisar o trabalho de Ricardo Salles, 0 Império do Brasil no contexto do século XIX. Escravidão nacional, classe senhorial e intelectuais na formação do Estado, que foi apresentado primeiramente no Fórum Almanack, no MAST, em 4 de novembro de 2011.

Tendo como baliza o Segundo Reinado, "mais precisamente, entre 1847, ano de criação do cargo de Presidente do Conselho de Ministros, e 1889, ano da queda da monarquia", Ricardo Salles apresentou os conceitos de Estado, classe senhorial, intelectual orgânico e da elite intelectual com base na teoria marxista de Antonio Gramsci, e na leitura de Ilmar Rollof de Mattos, no livro 0 Tempo Saquarema. ${ }^{1}$

No tocante às fontes, Ricardo Salles trabalhou principalmente com os Gabinetes e Presidente do Conselho de Ministros (1847-1889), em virtude da importância do Rio de Janeiro (e do Partido Conservador) na composição dos gabinetes, refazendo não só os números apresentados pelo Prof. José Murilo de Carvalho ${ }^{2}$, como também apresentando uma perspectiva diferente da nossa colega do PRONEX Dimensões e fronteiras do Estado brasileiro no séc. $X I X$, a Silvana Barbosa. ${ }^{3}$

0 ponto de partida do texto foi de discutir a questão do Estado Imperial e as "quatro vertentes de interpretação sobre a natureza do Estado e do poder imperiais". Na visão de Ricardo Salles, "não se pode separar a relação Estado e classe", no caso Estado Imperial e a classe dominante senhorial, e esta última dos dirigentes-intelectuais Saquaremas (Partido Conservador). Na minha compreensão achei importante resgatar o conceito de dirigente e relacioná-lo com certo intelectual, no caso o intelectual orgânico (conferir o final deste texto). Entretanto, Ricardo Salles poderia debater um pouco mais com marxistas com concepções diferentes sobre o papel do dirigente. 0 intelectual marxista português João Bernardo, próximo de uma visão "luckacsiana", trabalhou com a idéia do dirigente (não no sentido de intelectual), mas da classe que dirige o Estado Amplo4, diferentemente do conceito gramsciano que enfatiza a importância do intelectual orgânico, ligado à classe dominante, na busca da hegemonia do Estado Ampliado. ${ }^{5}$

Retornando às quatro vertentes destacadas, Ricardo Salles privilegiou particularmente as duas últimas, a saber: "a vertente das elites regionais, dispersa pela historiografia atual, e expressa na tese da dominação tetrárquica das grandes províncias de Minas Gerais, Bahia, Pernambuco e Rio de Janeiro, de Sérgio Buarque de Holanda (1985)" e "a vertente da classe senhorial, como exposta por Ilmar Rohloff de Mattos (1987)".

Ficou explícito no texto, o porquê das escolhas, porém, na minha compreensão a leitura feita pela Maria Fernanda Martins sobre o Estado Imperial não se enquadrou na mesma vertente do "patrimonialismo e do clientelismo, atualizada em sua versão das redes familiares de interesse".6 0 dito trabalho, fruto da sua tese de doutorado ${ }^{7}$, além de trabalhar com 0 conceito de elite política para a compreensão do poder político do Estado Imperial, metodologicamente está relacionado com a perspectiva da micro-história italiana, enfatizando as famílias e as redes de sociabilidade para a compreensão do funcionamento de certas instituições imperiais, como foi o segundo Conselho de Estado, criado em 1842. ${ }^{8}$ Embora concordou com José Murilo de Carvalho, com base nos livros dos pareceres das seções do Conselho de Estado, que as decisões dessa instituição eram seguidas pelo Poder Executivo - dai o autor destacar no seu livro "0 Conselho de Estado: a cabeça do governo"9 - , Maria Fernanda criticou a visão do autor, pois, analisando outro corpus documental do Conselho, como as 
Rio de Janeiro: Civilizção Brasileira, 2000. A respeito da micro-história italiana cf. LIMA, Henrique Spada. A micro-história italiana: escalas, indícios e singularidades. Rio de Janeiro: Civilização Brasileira, 2006. Uma crítica à micro-história muito importante resgatando a longa duração e a estrutura está no texto de TOMICH, Dale. A Ordem do Tempo Histórico: a Longue Durée e a Micro-História. Almanack, Guarulhos, n.02, p.38-51, 2 semestre de 2011. http://www.almanack.unifesp.br/index.php/ almanack/article/view/746

9

CARVALHO, José Murilo de. Op. Cit, p.327-358.

10

MARTINS, Maria Fernanda Vieira. A Velha arte de governar: o Conselho de Estado no Brasil Imperial. Topoi, v.7, n.12, jan-jun-2006, p.196.

11

TILLY, Charles. Coerção, capital e estados europeus (990-1992). Tradução de Geraldo Gerson de Souza. São Paulo: EDUSP, 1996.

12

Ibidem, p.213

13

Ibidem.

14

PANG, Eul-Soo. In Pursuit of Honor and Power: Noblemen of the Southern Cross in NineteenthCentury Brazil. Tuscaloosa: University of Alabama Press, 1988.

15

SALLES, Ricardo. 0 Império do Brasil no contexto do século XIX. Escravidão nacional, classe senhorial e intelectuais na formação do Estado. Almanack, Guarulhos, n.04, nov/2012, p.8. Uma "curiosidade": Maria Carolina Soares Torres, uma das filhas de Cândido José Rodrigues Torres (Barão de Itambi) e irmão do visconde de Itaboraí, casou-se com José Antônio Soares Ribeiro, grande proprietário rural, futuro barão de Inoã. Do consórcio, nasceu em Paris Evelina Torres Soares Ribeiro, e que foi casada com Joaquim Nabuco. 0 "inimigo" político dos saquaremas, o liberal e abolicionista Nabuco foi casada com uma saquarema, o que possibilitou a ele a transferência de um capital simbólico e familiar muito importante. A respeito do capital simbólico e familiar cf. BOURDIEU, Pierre. Razões Práticas: sobre a teoria da ação. Campinas: Papirus, 1996.

16

MUASE, Mariana. As Memórias da Viscondessa: Família e Poder no Império. Rio de janeiro: Jorge Zahar Ed., 2008. Verificar também FERREIRA, Marieta de Moraes. Histórias de Familia: Casamentos, Alianças e Fortunas. Rio de Janeiro, Léo Chritino Editorial, 2008.

17

SALLES, Ricardo. 0 Império do Brasil no contexto do século XIX, Op. Cit., p.9.
Atas, apontou que não havia consenso entre os conselheiros. Em determinados temas, debates demonstrando diferentes posicionamentos foram feitos entre os conselheiros, e para Fernanda Martins, "o ato da consulta e o debate são mais significativos para a compreensão do papel da instituição do que a resolução final do monarca". ${ }^{10}$

Outro ponto a ressaltar no trabalho de Maria Fernanda Martins foi o de trazer para o campo da História, o trabalho de Charles Tilly, Coerção, capital e estados europeus (990-1992). ${ }^{11}$ Esta inclusão pela autora, demarca, a nosso ver, a diferença de concepção de Estado com relação à análise de Ricardo Salles. Embora possamos incluir a sociologia-histórica de Charles Tilly numa matriz weberiana, o autor vai muito além. Através de uma perspectiva comparada, analisou a formação dos Estados europeus e propôs uma nova interpretação sobre o processo que culminou na consolidação do Estado nacional moderno como padrão dominante entre os tipos de unidades políticas do continente. Um dos principais argumentos do autor foi de que os Estados europeus percorreram trajetórias muito distintas e que face às guerras, a ação coercitiva do Estado possibilitou "perceber um padrão de uniformidade e variação entre trajetórias de formação do Estado que empregaram intensa coerção".12 Portanto, mesmo com certa generalização nas comparações históricas dos Estados, na perspectiva de Charles Tilly, o Estado Nacional ocupou papel relevante na compreensão do sistema político-econômico que passou a predominar no mundo Ocidental a partir da Era Moderna. ${ }^{13}$

Contrapondo às perspectivas destacadas, para a compreensão do cargo de Presidente do Conselho de Ministros, criado pelo decreto ${ }^{\circ} 523$ de 20 de julho de 1847, Ricardo Salles enfatizou e relacionou tal instituição como expressão do predomínio político de uma facção específica, no interior do partido conservador, o grupo dos Saquaremas. Para Ricardo Salles, a Trindade Saquarema, constituida por Paulino Soares de Souza (Visconde de Uruguai), Joaquim José Rodrigues Torres (Visconde de Itaboraí) e Eusébio de Queiroz Matoso da Câmara, constituiu-se numa Elite Estadista, conceito este diferente da Elite Política proposta por José Murilo de Carvalho e das tipologias de Soo Pang ${ }^{14}$. No entendimento de Salles, "o grupo teve sua alcunha derivada da região em que seus principais líderes, Joaquim José Rodrigues Torres (1802-1872), futuro visconde de Itaboraí, e Paulino José Soares de Sousa (1807-1866), futuro visconde de Uruguai, tinham sua base social e política. Os dois eram casados com filhas de João Álvares de Azevedo, grande proprietário rural na região". ${ }^{15}$ Esta região era a Raiz da Serra, e através de pequenas biografias, Ricardo Salles acabou reconstruindo a ligação dos Saquaremas com as famílias do Vale do Paraíba, a base social do Partido Conservador, através dos laços de casamento. Mariana Muaze, através da análise da família Ribeiro Avelar, percebeu a importância da rede de sociabilidade que permitiu a essa família se destacar na região do Vale do Paraiba fluminense, e estender o seu poder em direção à Corte no Rio de Janeiro. ${ }^{16}$

Ligado ao grupo Saquarema estavam Bernardo Pereira de Vasconcelos, José Clemente Pereira, Honório Hermeto Carneiro Leão, que para Ricardo Salles foram "os principais articuladores do Regresso conservador e da reabertura na prática do tráfico de escravos, proibido por lei a partir de 1831", mostrando "os laços entre a grande propriedade e o poder na província e na cidade do Rio de Janeiro"17. Aqui valeu uma ressalva. No caso de José Clemente Pereira, Julio Bentivoglio (também pesquisador 
18

A respeito da trajetória de Paulo Barbosa cf. COSTA, Maria Cristiane da. Práticas de pensões de estudos no Império: um olhar sobre pensionários militares (1825). Niterói, 2012. Dissertação (Mestrado em História). Universidade Federal Fluminense, Programa de Pós-graduação, 2012

19

SALLES, Ricardo. 0 Império do Brasil no contexto do século XIX, Op. Cit., p.10.

20

SALLES, Ricardo. Nostalgia Imperial: a Formação da Identidade Nacional no Brasil do Segundo Reinado. Rio de Janeiro: Topbooks, 1996.

21

0 peso sobre as províncias do Norte na Guerra do Paraguai fez com que as "velhas rusgas" entre 0 Norte e o Sul, desde os tempos de D. João VI e de D. Pedro I, retornassem pós-1870. MELLO, Evaldo Cabral de. 0 Norte Agrário e o Império, 1871-1889. 2a ed. revista. Rio de Janeiro: Topbooks, 1999.

22

Eu tenho muitas dúvidas se José Maria da Silva Paranhos, o Visconde do Rio Branco, pai do famoso Barão do Rio Branco, se considerava um baiano, defendendo os interesses de um grupo regional especifico. A sua vida politica e profissional foi feita no Rio de Janeiro.

23

Embora datado, e necessitando de uma revisão bibliográfica, Ricardo Salles tem um livro muito interessante sobre a Guerra do Paraguai. Cf. SALLES, Ricardo. Guerra do Paraguai, escravidão e cidadania na formação do exército. Rio de Janeiro: Ed. Paz e Terra, 1990. do PRONEX) o associou com o Clube da Joana ou a facção Áulica, liderada pelo Aureliano de Sousa e Oliveira Coutinho (1 ${ }^{\circ}$ e único Visconde de Sepetiba) e ao mordomo imperial Paulo Barbosa ${ }^{18}$. Julio incluiu, também, o Marquês de Olinda a tal facção, que juntamente com o partido liberal forjaram o golpe da maioridade.

Importante ressaltar que, para Ricardo Salles, as principais questões que nortearam a atuação dos saquaremas e de outros conservadores da Bacia do Paraíba foram: "a defesa dos interesses dos grandes proprietários rurais, particularmente da região da província fluminense e da Bacia do Paraíba; a defesa da escravidão, seja em sua forma dependente do tráfico internacional, seja, depois de 1850 , em sua forma nacional, com a tendência à reprodução natural positiva da população escrava; o Estado monárquico centralizado e representativo na forma que este adquiriu a partir dos anos de 1840". Tais políticas, entretanto, só foram possíveis graças ao predomínio dos Saquaremas a frente do Estado, ou seja, o " predomínio saquarema foi exercido através da direção moral e intelectual hegemônica que esses homens imprimiram em seu tempo". Para Ricardo Salles, tal predomínio foi alcançado não apenas "quando eles ou políticos com eles identificados estiveram diretamente no governo: entre 1848 e 1852, nos ministérios de Olinda, Monte Alegre e de Joaquim José Rodrigues Torres; entre 1856 e 1857, no ministério do marquês de Caxias; entre 1868 e 1870, novamente em ministério de Rodrigues Torres, então visconde de Itaboraí; e, finalmente, entre 1875 e 1878, no ministério do já então duque de Caxias". Em outras palavras, "durante onze anos arredondados dos 42 de que estamos falando".19

Portanto, até a crise política de 1868 , a concepção saquarema de Império predominou mesmo quando eles não estiveram no governo, o que reforçou a sua leitura do livro A Nostalgia Imperial, sobre a crise do Estado Imperial pós-1870. Para Salles, "a queda do regime monárquico, entretanto, se deu exatamente no momento em que a ordem social escravista, submetida à profunda contestação e convulsões sociais, havia sido derrubada".20

A leitura sobre o pós-1870 e, principlamente sobre a crise do escravismo associada ao aparecimento de novos grupos sociais ou classes, além do abolicionismo, poderia ter sido aprofundada com um maior debate com autores como Evaldo Cabral de Melo e seu livro pouco comentado o Norte Agrário. ${ }^{21}$ No entendimento de Evaldo, a ruptura e as diferentes posições entre o Norte e o Sul aprofundaram-se com o final da Guerra do Paraguai (1864-1870) e o gabinete do liberal baiano Visconde do Rio Branco (1871-1875). ${ }^{22}$ Aqui, novamente, a questão da guerra, no caso a Guerra do Paraguai, poderia ser melhor discutida. ${ }^{23} \mathrm{~A}$ guerra, se num primeiro momento, conseguiu a coesão e "tampar" questões como a emancipação dos escravos e reformas políticas e na justiça, o seu final permitiu acelerar um processo de desarticulação e crise da hegemonia do projeto Saquarema de Poder. Como muito bem destacou Joaquim Nabuco, a Guerra do Paraguai foi um divisor de águas, pois, além de marcar o seu apogeu, também se constituiu no declínio do Império brasileiro.

Uma divergência com Ricardo Salles consistiu na ênfase sobre o poder econômico dos fazendeiros. Como destacou no texto, "economicamente, os negócios dos grandes fazendeiros eram mais avultados, diversificados, complexos e mais seguros e lucrativos do que o comércio e o rentismo urbano [...]. 0 espírito empresarial de busca do lucro era, assim, parte constitutiva do éthos senhorial. A honra da nobreza era almejada e 
SALLES, Ricardo. 0 Império do Brasil no contexto do século XIX, Op. Cit., p.42.

25

Nas matrículas do Tribunal do Comércio, criado com o Código Comercial de 1850, os negociantes se matriculavam como negócio de grosso. Como exemplo temos João P. Darrigue Faro, $2^{\circ}$ barão, depois Visconde do Rio Bonito, matriculado como Comércio de Comissão de Grosso Trato de Comissão. GUIMARÃES, Carlos Gabriel. A presença inglesa nas Finanças e no Comércio no Brasil Imperial: os casos da Sociedade Bancária Mauá, MacGregor \& Co. (1854-1866) e da firma inglesa Samuel Phillips \& Co. (1808-1840). São Paulo: Alameda/FAPERJ, 2012 (no prelo).

26

A imobilização do capital em bens imóveis era, e é até hoje, uma estratégia de acumulação da riqueza. Embora o trabalho de João Fragoso e Manolo Florentino tinha como principal preocupação compreender a reprodução da economia colonial, particularmente a do Rio de Janeiro, na fase descendente (de crise) do ciclo de Kondratief da economia mundial, que corresponderia à crise do Antigo Sistema Colonial, os investimentos em propriedades e bens semoventes (escravos e outros) faziam parte de uma racionalidade econômica que não era arcaica. A economia escravista, ou melhor, a formação econômica e social escravista não era capitalista e, para analisá-la, assim como a atuação dos indivíduos, temos que compreendê-la como um todo, articulando o econômico, social, político e cultural. Como destacou Karl Polanyi, "a economia do homem encontra-se, regra geral, submergida nas suas relações sociais". CF. POLANYI, Karl. A nossa obsoleta mentalidade mercantil. Revista Trimestral de História e Idéias, n.1, 1977, p.7-19; FRAG0SO, João Luiz R. e FLORENTINO, Manolo. 0 arcaísmo como projeto: mercado atlântico, sociedade agrária e elite mercantil em uma economia colonial tardia. Rio de Janeiro: Civilização Brasileira, 2001.

27

0 clássico trabalho do Maurice Godelier também possibilita pensar sobre a racionalidade econômica dos fazendeiros, que não era a moderna racionalidade capitalista. GODELIER, Maurice. Racionalidade e Irracionalidade na Economia. Rio de Janeiro: Ed. Tempo Brasileiro, 1976.

28

GUIMARÃES, Carlos Gabriel. A presença inglesa nas Finanças e no Comércio no Brasil Imperial, Op. Cit.

29

Em trabalho recente, numa documentação do State of Papers do governo britânico de 1829, encontrei o nome de Antonio Clemente Pinto, futuro barão de Nova Friburgo, empreendendo uma carregação de escravos. No mesmo documento apareceu João Rodrigues Pereira de Almeida, Barão de Ubá, o primeiro barão de café do vale do Paraíba fluminense, com 3 carregações de escravos no ano. GUIMARÃES, Carlos Gabriel. 0 "comércio de carne humana" no Rio de Janeiro: o negócio do tráfico negreiro de João Rodrigues Pereira de Almeida e da firma Joaquim Pereira de Almeida \& Co., 1808-1830 - primeiros esboços In: BITTENCOURT, Marcelo, GEBARA, Alexsander e RIBEIRO, Alexandre (org.). África passado e concedida pelo serviço ao Estado e pela benemerência que a riqueza propiciava. Era uma nobreza de honra e de poder, da civilização e do progresso, condição que nem todos conseguiam". ${ }^{24}$

Não negamos a riqueza dos barões, porém acreditamos que ela não era maior do que a dos negociantes de grosso trato da cidade do Rio de Janeiro ${ }^{25}$ - necessário verificar e confrontar os inventários em diferentes épocas. Concordo com Ricardo, e várias pesquisas têm ressaltado que os fazendeiros (e também suas viúvas) não eram arcaicos ${ }^{26}$, e tinham uma racionalidade econômica, com todo perigo que envolve esta palavra. ${ }^{27}$ No meu entendimento, a consolidação do projeto Saquarema só foi possivel quando as demais frações da classe senhorial, como os negociantes e os capitalistas (não no sentido moderno, e sim como personificação do capital usurário), participaram do processo sob a direção dos Saquaremas. Importante lembrar que foi no Gabinete Conservador de 1848, que reformas intitucionais aconteceram e cristalizaram o que Ilmar de Mattos destacou sobre a Manutenção dos Monopólios. Entre essas reformas destacamos o Código Comercial (junho de 1850) e a Lei de Terras e o fim do Tráfico de Escravos Atlântico (ambos de setembro de 1850), que beneficiaram não só os fazendeiros do Centro-Sul, mas, principalmente, os negociantes de grosso trato. A participação de Irineu Evangelista de Souza, futuro barão, depois, visconde de Mauá, diretor da firma inglesa Carruthers \& Co., ex-presidente da mais poderosa Praça Comercial do Império, a Sociedade dos Assinates da Praça do Rio de Janeiro (em 1867, Asssociação Comercial do Rio de Janeiro) na comissão organizadora do Código Comercial, teve relação direta com a negocianção entre as frações da classe dominante senhorial para a consolidação do Estado Imperial. Como destacou outro membro da comissão, o barão de Penedo: o Barão de Mauá era por esse tempo geralmente considerado de grande importância na praça do Rio de Janeiro"28.

Alguns ditos fazendeiros, que acumularam grandes fortunas, como o Comendador Valim (Bananal/São Paulo) e o Barão de Nova Friburgo (Cantagalo/RJ), esse último acionista e diretor da Caixa Econômica junto com o barão de Mauá, jamais abandonaram o comércio, e nos seus ativos (inventários), além de letras do tesouro, ações e outros, havia uma grande parcela composta de divida ativa, ou seja, empréstimos e créditos para outros. ${ }^{29} \mathrm{Em}$ face de tal perfil, João Fragoso e Ana Rios denominaram de "fazendeiros-capitalistas". ${ }^{30}$

Ainda com relação à riqueza e aos negócios envolvendo fazendeiros e negociantes, se verificarmos a cadeia de crédito, historicamente sempre houve uma queixa generalizada dos fazendeiros contra os detentores do crédito, e no caso da cafeicultura do século XIX, desde o papel dos intermediários, no caso os comissários, até os bancos/banqueiros (por mais que casamentos aconteceram entre os filhos dos credores e devedores). Novas pesquisas ressaltaram que, muitas vezes, os fazendeiros responderam com a organização de casas comerciais que serviram de intermediários entre o produtor e o ensacador (armazém) e as casas exportadoras. Entretanto, e de um modo geral, não foi esta a conduta majoritária. ${ }^{31} \mathrm{Em}$ meados da década de 1850, Luiz Peixoto de Lacerda Werneck, advogado e fazendeiro, filho primogênito de Francisco Peixoto de Lacerda Werneck, o barão com grandeza de Pati do Alferes, fez um livro criticando os juros e práticas dos bancos comerciais no tocante às concessões de crédito para os fazendeiros. $^{32}$ Essa queixa não era nova, pois, em 1848, o liberal paraense Bernardo 
presente: II encontro de estudos africanos da UFF. Niterói: PPG-HISTÓRIA-UFF, 2010 (e-book)

30

FRAGOSO, João L. Ribeiro e RIOS, Ana Maria Lugão. Um empresário brasileiro no oitocentos. In: MATTOS, Hebe M. de e SCHNOOR, Eduardo (org.). Resgate: uma janela para o oitocentos. Rio de Janeiro: Topbooks, 1995. p.199

31

A respeito do papel do intermediário, principalmente dos comissários, conferir o importante trabalho de SWEIGART, Joseph E. Coffe factorage and the emergence of a Brazilian Capital Market, 1850/1888. New York/London: Garland Publishing, 1987.

32

WERNECK, Luiz Peixoto de Lacerda. Estudos sobre o crédito rural e hipotecário. Rio de Janeiro: Garnier, 1857.

33

SOUZA FRANCO, Bernardo de. Os Bancos do

Brasil: sua história, defeitos de organização atual e reforma no sistema bancário. 2a ed. Brasília: Ed UNB, 1984 (a primeira edição foi de 1848).

34

SALLES, Ricardo. 0 Império do Brasil no contexto do século XIX, Op. Cit., p.42.

PANG, Eul-Soo. Op. Cit.

SALLES, Ricardo. 0 Império do Brasil no contexto do século XIX, Op. Cit., p.31.

37

CAIN, J.P. \& HOPKINS, A.G. Gentlemanly

Capitalism and British Expansion Overseas I. the Old Colonial System, 1688-1850. The Economic History Review, 2nd ser.XXXIX, n.4 (1986), p.501525; JONES, Charles. International Business in the 19 th century. The rise and fall of a cosmopolitan burgeoisie. Great Britain: Wheatsheaf Books, 1987 de Souza Franco, futuro ministro da fazenda em 1857-1858, conselheiro e Visconde de Souza Franco, escreveu um livro onde relatou a atividade bancária desenvolvida na época e as dificuldades dos bancos em emprestar para os fazendeiros..$^{33}$

Outro ponto de destaque do texto foi o debate com autores como Eul-Soo Pang acerca da utilização do conceito de classe senhorial em detrimento de elite. Como destacamos no início, Ricardo Salles, baseado em Antonio Gramsci, enfatizou que a classe senhorial deve ser entendida como "uma classe nacional - expressão tomada de Antonio Gramsci - não no sentido de que ocupasse todo o território nacional e nele se configurasse de forma homogênea, mas no sentido de que sua dominação foi nacional, organizada a partir do Estado, submetendo e incorporando interesses de outros grupos e classes sociais, tanto da sua quanto de outras regiões do Império". Não querendo estender em demasia com citações, porém não tive como não citar, Ricardo Salles, vai além, quando destacou que a "[...] a classe senhorial se constituia numa aristocracia em que riqueza, posição social, poder político e, em menor grau, prestígio junto à dinastia e origem familiar eram os sinais e os fatores de status. Uma aristocracia aburguesada, que tinha, em Napoleão, seu mito e seu fantasma".34

A expressão aristocracia aburguesada, mesmo que paradoxal, foi utilizada para se contrapor a expressão "gentry empreendedorae capitalista" utilizada por Eul-Soo Pang ${ }^{35}$, quando este designou a mentalidade e a inserção dos grandes fazendeiros ou plantadores escravistas do Centro-Sul do Brasil do século XIX no sistema internacional do capitalismo histórico, diferentemente de "uma nobreza mais antiga, de origens no período colonial, mais ligada ao Norte e ao açúcar".

Além desta distinção entre a nobreza imperial, Soo Pang "em outro plano, também faz uma distinção entre os setores nobres e de elite moderadamente ricos, que estariam mais ligados à política e ao Estado patrimonialista, os mandarins, e aqueles mais ligados ao mundo econômico. Nobres e plantadores mais ricos confinariam a si mesmos na política local e regional, uma vez que os negócios mais dinâmicos da produção de café e açúcar requereriam maior atenção e presença direta". Para Ricardo Salles, a leitura de Soo Pang levou a uma espécie de "'divisão de trabalho' entre os nobres - e, por tabela, a elite de uma maneira geral - que se dedicavam mais aos assuntos do governo e os nobres e membros da elite mais apegados à administração dos negócios ligados ao mercado mundial capitalista, fossem estes plantações voltadas para a exportação e/ou para investimentos urbanos e financeiros [...]"36.

Concordando com Ricardo Sales de que a visão de Soo Pang foi estática, e de que não se pode separar uma "elite econômica" de uma "elite política", uma questão não foi resolvida: 0 que é ser aristocracia burguesa? 0 conceito de burguesia junto ao de aristocracia lembrou-me de certas definições utilizadas por historiadores econômicos ingleses para definir as atividades econômicas, políticas e culturais dos "merchants" ingleses do século XIX. Charles Jones utilizou o termo "cosmopolitan burgeoisie", e J. P. Cains e A. G. Hopskins adotou "gentlemanly capitalism" ${ }^{37}$. Há um grande debate sobre tais expressões, pois, no entendimento destes autores, não só a política macro do Estado britânico estava nas "mãos" de uma coalizão política da aristocracia e grandes negociantes (banqueiros, mercadores do comércio importador-exportador e outros), como também o próprio comportamento dos ditos mercadores. 
38

A respeito do conceito de habitus cf. BOURDIEU,

Pirre. Sociologia (organização de Renato Ortiz).

São Paulo: Ática, 1983; SETTON, Maria da Graça

J. A teoria do habitus em Pierre Bourdieu: uma

leitura contemporânea. Anped, 2002: http://www. anped.org.br/rbe/rbedigital/RBDE20/RBDE20_06_ MARIA_DA_GRACA_JACINTHO_SETTON.pdf

39

A respeito do conceito de elite há uma extensa bibliografia. Para o nosso estudo Cf. BOBBIO, Norberto. Elite, Teoria das. In: BOBBIO; Norberto, MATTEUCCI, Nicola, PASQUINO, Gianfranco. Dicionário de Política. Vol.1. Tradução de Carmem C Varriale et alli; Coord. Trad. João Ferreira; Revisão Geral João Ferreira e Luiz Guilherme Pinto Cacais. Brasília: Ed. UNB, 1998. p.385-391; GRYSNPAN, Mario. Ciência, política e trajetórias sociais: uma sociologia histórica da teoria das elites. Rio de Janeiro: Ed. fundação Getúlio Vargas, 1999.

40

A respeito da influência do conceito de elite no marxismo verificar BOOTOMORE, Tom. Elite. (ed.). Dicionário do Pensamento Marxista.

Tradução de Waltensir Dutra; Revisor técnico e pesquisa bibliográfica Antonio Monteiro Guimarães. Rio de Janeiro: Jorge Zahar Ed., 1988. p.122-123.

41

SALLES, Ricardo. 0 Império do Brasil no contexto do século XIX, Op. Cit., p.32. Destaque meu.

42

Ibidem. Destaque meu.

43

Ibidem, p.10.

44

Ver o verbete sobre Antonio Gramsci, In: BOTTOMORE, Tom (ed). Dicionário do Pensamento Marxista. Edição brasileira organizada por Antonio Monteiro Guimarães. Rio de Janeiro: Jorge Zahar Ed.1988. p.166.
Senti falta, também, do Edward P. Thompson para o conceito de classe senhorial, pois o autor inglês foi utilizado por Ilmar de Mattos. 0 "habitus" ou "estilo de vida" senhorial consistiu num dos principais atributos dessa classe. ${ }^{38}$

Outra questão importante para o debate foi a utilização do conceito de elite estadista por Ricardo Salles. Embora o conceito de elite seja bastante amplo e complexo ${ }^{39}$, e mesmo sendo de oposição ao marxismo como proposto por Vilfredo Pareto e Caetanos Mosca, o conceito acabou por influenciar marxistas como o próprio Antonio Gramsci. ${ }^{40}$ Para Ricardo Salles foi muito importante a ação de uma elite estadista, no caso os saquaremas, para a coesão no interior da classe senhorial.

Finalizando as minhas observações sobre o importante e abrangente texto do Ricardo Salles, e de certa forma relacionadas com o que destaquei acima, tivemos a importância do papel do intelectual. A filiação do Ricardo Sales à matriz marxista de Antonio Gramsci ficou ainda mais explícita quando associou intelectuais à classe dirigente. Para Ricardo Salles, "fica claro que as categorias de intelectuais, enquanto um grupo social de origens diversificadas, mas organicamente ligado a um Estado e, por essa ligação orgânica, se torna de classe, e de classe social mostram maior valor explicativo".41 No longo prazo e alcance, foram os interesses da grande propriedade escravista, mais especialmente da grande propriedade escravista da Bacia do Paraíba do Sul, que prevaleceram, umas vezes mais, outras vezes menos independente das intenções e motivações imediatas deste ou daquele agente. "Os intelectuais eram assim representantes e, mais importante, dirigentes da classe senhorial, e não de si mesmos. Quando deixaram de sê-lo, na conjuntura pautada pela ascensão do movimento abolicionista e das lutas escravas, entre 1885 e 1888, o Estado imperial caiu"42

Ricardo Salles avançou, e muito, na discussão teórica sobre o intelectual, destacando diversas leituras de Max Weber, K. Manhein, N. Bobbio e outros. Através de Gramsci, ele questionou tais autores, pois "os intelectuais são um grupo autônomo e independente, ou cada grupo social tem sua própria categoria especializada de intelectuais?" ${ }^{143} \mathrm{~A}$ partir daí, Gramsci, numa perspectiva histórica, apresenta dois tipos de intelectuais: o orgânico e o tradicional. Vinculado a um grupo social, o intelectual orgânico pode ser visto como um organizador da produção de um novo modo cultural (destaque meu). [...] Já o intelectual tradicional, "comprometido com uma certa tradição que remonta a um período histórico mais antigo" ${ }^{44}$, guarda um distanciamento do grupo social hegemônico.

Entretanto, questões surgiram, mesmo enfatizando a importância de se trabalhar com o Gramsci, a saber: Os intelectuais como dirigentes são os intelectuais orgânicos? Como ficou a questão da construção da hegemonia por parte dos intelectuais orgânicos? Qual foi a Escola (no sentido mais amplo) dos intelectuais no Império e onde estavam os aparelhos privados de hegemonia numa sociedade escravista onde a sociedade civil era "fraca" em detrimento de uma sociedade política forte?

As questões acima não invalidaram a perspectiva do Ricardo Salles, e o texto apresentado para a discussão mostrou o quanto o autor foi sólido na sua perspectiva teórica e metodológica. A minha contribuição para o debate foi de levantar questões que não ficaram claras. 